\title{
Métodos alternativos ao uso de animais para a detecção de pirogênio: oportunidades e desafios no controle da qualidade de produtos biológicos
}

\author{
Elaine Cristina Azevedo Navega ${ }^{1}$; Cristiane Caldeira da Silva ${ }^{2}$; Octavio França \\ Presgrave ${ }^{2}$; Alessandra Santos Almeida1; Isabella Fernandes Delgado3; \\ Katherine Antunes de Mattos ${ }^{1}$
}

\author{
1- Laboratório de Controle de Qualidade, Departamento de Qualidade do Instituto de Tecnologia em \\ Imunobiológicos, Fundação Oswaldo Cruz, Brasil. \\ 2- Departamento de Farmacologia e Toxicologia, Instituto Nacional de Controle de Qualidade em Saúde, \\ Fundação Oswaldo Cruz, Brasil. \\ 3- Vice Diretoria de Pesquisa e Ensino do Instituto Nacional de Controle de Qualidade em Saúde, Fundação \\ Oswaldo Cruz, Brasil. \\ ${ }^{1}$ Correspondência: katherine.antunes@yahoo.com.br
}

RESUMO: A necessidade de alternativas ao uso de animais no teste de pirogênio foi guiada pelo princípio dos 3R's, culminando no desenvolvimento e aceitação pela Farmacopeia Europeia do método alternativo in vitro, o Teste de Ativação de Monócitos (Monocyte Activation Test - MAT, 2.6.30/ 2010). O MAT utiliza como matriz, fontes de monócitos humanos (sangue total, PBMC, linhagens celulares), respeitando o conceito dos 3R's e excluindo riscos inerentes à extrapolação interespécies. É um método promissor e eficiente, que detecta um amplo espectro de pirogênios e supri limitações dos testes atuais preconizados pelas farmacopeias, o teste in vitro de Endotoxina Bacteriana e o Teste de Pirogênio em Coelhos. Apesar das vantagens abordadas, alguns obstáculos técnicocientíficos e regulatórios devem ser transpostos para a implantação efetiva do MAT na rotina industrial, em especial de produtos biológicos.

Palavras-chave: métodos alternativos, pirogênio, Teste de Ativação de Monócitos, produtos biológicos, 3R's

ABSTRACT: The need for alternatives to animal use was guided by the 3R's principle and culminated in the development and acceptance by European Pharmacopoeia of the in vitro alternative method, the Monocyte Activation Test (MAT, 2.6.30/ 2010). MAT uses as matrix human monocytes sources (whole blood, PBMC, or cell lines) respecting the concept of the 3R's and excluding inherent risks to inter-species extrapolation. This is a promising and efficient method, which detects broad spectrum of pyrogens and cover limitations of current recommended pharmacopoeial in vitro test the (Bacterial Endotoxin) and the Rabbit Pyrogen Test. Despite the advantages addressed to MAT, some technical-scientifics and regulatories roadblocks may be transposed to its effective implementation in the industrial routine, especially for biological products.

Key Words: alternative methods, pyrogen, Monocyte Activation Test, biological products, 3R's. 


\section{HISTÓRICO}

Pirogênios são, por definição, substâncias indutoras da febre provenientes de bactérias, vírus ou fungos. Estas substâncias são potenciais causadoras de reações inflamatórias sistêmicas e locais, com graus de intensidade que variam desde aumento da temperatura à morte (Dinarello et al., 2004).

A importância da detecção dos pirogênios na indústria farmacêutica se destaca na possível contaminação de parenterais, sendo o teste de pirogênio uma exigência desde o surgimento do das soluções parentais de grande volume nos anos 1930. Isso chamou a atenção para a necessidade de um teste oficial, que foi reforçada pela forte demanda destes produtos na II Guerra Mundial. Um estudo conjunto foi iniciado para desenvolver o Teste de Pirogênio em Coelhos (Rabbit Pyrogen Test - RPT) (Welsh et al., 1943; McClosky et al., 1943, Williams, 2007), o que conduziu à incorporação deste ensaio em parenterais em diversas farmacopeias como: Farmacopeia Americana - USP (1942); Farmacopeia Europeia - FE (1971) e Farmacopeia Brasileira - FB (1976), sendo uma obrigatoriedade antes da liberação de cada lote.

Várias limitações do teste com animais, tais como, questões éticas, manejo dos animais e variabilidade biológica estimularam o desenvolvimento de métodos alternativos. Levin e Bang (1964) demonstraram que a hemolinfa do caranguejo-ferradura, Limulus polyphemus, coagula quando em contato com a endotoxina, sendo este o princípio do teste de Limulus Amoebocyte Lysate ( $\mathrm{LAL}$ ), que é utilizado para detectar a contaminação por endotoxina (lipopolissacarídeos, LPS de origem Gram-negativas) em algumas drogas parenterais. Entretanto, o LAL ou teste de endotoxina bacteriana não é capaz de substituir por completo o RPT, uma vez que por definição, ele é um teste de detecção de endotoxina, e não um teste de pirogênio, pois falha em reconhecer outras classes de pirogênios como Gram-positivas, fungos, vírus e toxóides (Poole e Gaines Das, 2001).

Assim, o debate sobre a possibilidade de desenvolver cientificamente alternativas válidas aos experimentos em animais (principalmente os sencientes) e com a capacidade de detecção de um amplo espectro de pirogênios vem ganhando destaque. A partir desta proposta, uma nova geração de métodos alternativos, tem sido desenvolvida com o objetivo de melhor esclarecer os mecanismos dos processos de saúde humana e diminuir os impactos ambientais pela redução, substituição ou refinamento na experimentação animal (Russel e Burch, 1959). Os princípios dos 3R's preconizam os conceitos da (i.) substituição da experimentação animal pelos ensaios in vitro utilizando associação de células animais e culturas de tecido, métodos físico-químicos e ensaios in silício utilizando a bioinformática, da (ii.) redução que tem como objetivo diminuir o número de animais (iii.) refinamento que visa utilizar os avanços tecnológicos direcionados para endpoints humanos, trazendo maior relevância para os resultados, além da preocupação com o bem-estar animal. Assim, o desenvolvimento e implementação dos métodos alternativos requer estratégias integradas através da cadeia de pesquisa fundamental e aplicada, além da aprovação regulatória (Cazarin et al., 2004).

O potencial alvo para a substituição de animais por métodos alternativos são os testes de segurança e eficácia em escala industrial exigidos pelas agências regulatórias. Muitos sistemas de aceitação internacional são baseados no sistema de experimentação animal e cada vez mais ganha aceitação para inovações alternativas (Ashton et al., 2014). Especificamente com relação ao ensaio de pirogênio, as múltiplas limitações de métodos existentes e o acúmulo de conhecimento científico no campo da imunologia contribuíram para o desenvolvimento de um método alternativo baseado no mecanismo de reação da febre no mamífero, o Teste de Ativação de Monócitos (Monocyte -Activation Test MAT) (Gaines Das et al., 2004).

Apesar das vantagens decisivas do MAT, tais como aplicação in vitro, alta sensibilidade e reconhecimento de um amplo espectro de pirogênios que levaram a sua aceitação como terceiro método para o teste de pirogênio pela FE (Monocyte Activation Test, 2.6.30, 2010), algumas dificuldades relacionadas à aplicação do MAT ainda devem ser superadas, tais como, obtenção e qualificação das matrizes celulares, necessidade de validação por produto e maior robustez científica, conforme argumentado pelo Comitê Organizador 
Interagências para Validação de Métodos Alternativos (ICCVAM). Assim, esta revisão aborda o potencial do MAT como teste de pirogênio alternativo ao uso de animais no controle da qualidade de produtos biológicos e alguns desafios técnico-científicos e regulatórios, que devem ser transpostos para a efetiva incorporação às principais farmacopeias internacionais e nacional e sua aplicação em escala industrial.

\section{ESTADO ATUAL DE ACEITAÇÃO REGULATÓRIA}

O RPT e o LAL são aplicados no controle da qualidade de medicamentos parenterais e dispositivos médicos por mais de 60 e 30 anos, respectivamente. Hoje em dia, uma crescente necessidade de novos métodos alternativos é explicada pelas várias limitações dos métodos em vigência e a tendência mundial a substituição do uso de animais.

A avaliação da confiabilidade e da relevância de alguns métodos alternativos de detecção de pirogênios foi desenvolvida pelo Centro Europeu de Validação de Métodos Alternativos (ECVAM) e possui aceitação internacional (Hoffmann, 2005). Como o MAT tem provado ser uma alternativa adequada aos testes de pirogênios, vários grupos científicos concentraram na validação formal desta metodologia, seguindo as orientações fornecidas pelo ECVAM (Hoffmann et al., 2005; Schindler et al., 2006).

Entretanto, os estudos de validação têm sido criticados especialmente por utilizarem exclusivamente a endotoxina (LPS) como estímulo pirogênico padrão (Spreitzer et al., 2007), mesmo tendo uma abundância de dados científicos sobre a reatividade de monócitos humanos frente ao ácido lipoteicóico (LTA) altamente purificada (Hermann et al., 2001; Opitz et al., 2001) e outros pirôgenios não-endotoxinas (Hasiwa et al., 2013). A problemática na validação com pirogênios nãoendotoxinas pode estar relacionada à pouca disponibilidade comercial de um padrão nãoendotoxina internacional devido à baixa qualidade e disponibilidade destas moléculas purificadas (Spreitzer et al., 2007).

Atualmente estão validados 5 testes alternativos in vitro para detecção de pirogênios baseados no princípio do MAT1. Conforme parecer técnico emitido pelo ICCVAM, para o uso destas técnicas cada produto deve ser validado especificamente, sendo necessária a equivalência ao teste in vivo (Poole et al., 1998, ICCVAM, 2008). Assim, o ICCVAM e o FDA (U.S. Food and Drug Administration) aprovaram a utilização desse método in vitro para cloreto de sódio $0,9 \%$, glicose $5 \%$, etanol $13 \%$, ocitocina, metoclopramida, ampicilina, maleato de dimetindeno, ranitidina e tartarato de metoprolol, sendo necessária uma análise caso-a-caso para a detecção de endotoxina de soluções parenterais (ICCVAM, 2008, 2009; FDA, 2009). Até o momento, outras farmacopeias não incorporaram o MAT, apesar de um parecer do esforço para aceitação deste teste em países como Brasil e Cuba (Hartung, 2015).

No Brasil, a Agência Nacional de Vigilância Sanitária (Anvisa) tem adotado medidas de incentivo e desenvolvimento de métodos alternativos, como o apoio à criação do Centro Brasileiro de Validação de Métodos Alternativos - BraCVAM, ligado ao Instituto Nacional de Controle de Qualidade em Saúde (INCQS)/Fiocruz, e sua efetiva participação na Rede Nacional de Métodos Alternativos (RENAMA), do governo federal. Criado em 2012, o BraCVAM organiza a expertise e a demanda nacional por métodos alternativos em pesquisas científicas, junto com 0 Conselho Nacional de Experimentação Animal (CONCEA) e a RENAMA (Presgrave et al., 2014). Recentemente, o CONCEA reconheceu 17 métodos alternativos ao uso de animais em atividade de pesquisa (Brasil, 2014) ficando estabelecido "o prazo de até 05 (cinco) anos como limite para a substituição obrigatória do método original pelo método alternativo".

\section{VANTAGENS DO MAT COMO MÉTODO ALTERNATIVO}

O RPT tem sido tradicionalmente recomendado pelas farmacopeias para avaliar contaminantes pirogênicos em parenterais, dispositivos médicos e produtos biológicos (Welch et al., 1943, Du et al., 2011). Entretanto, dentre os fatores limitantes deste teste estão o manejo dos animais, a confiabilidade dos ensaios (resultados falsopositivo ou falso-negativos) (Grant, 1950, Hartung, 2015), o fato de não ser quantitativo (teste limite), não utilizar controle positivo, não possuir diferencial de sensibilidade aos pirogênios devido a extrapolação interespécies (coelho/homem) (ICCVAM, 2008), restritiva aplicabilidade a uma gama 
de produtos farmacêuticos modernos (radiofármacos, analgésicos, biofármacos, drogas imunomodulatórias e drogas contra câncer) que não podem ser testados em coelhos devido aos efeitos interferentes (Hartung et al., 2001; Hartung, 2015) por influenciarem na regulação da temperatura ou por causarem reações. Além disso, o RPT não pode ser utilizado para testes de preparações celulares (Hartung et al., 2001) (Tabela 1).

Outro teste para detectar a pirogenicidade - o LAL, utiliza a hemolinfa do crustáceo Limulus polyphemus para detectar LPS, desde que este se encontre disponível na forma livre. A incapacidade de detectar outras diferentes fontes potenciais de pirogênios (bactérias Gram-positiva, fungos e vírus), não menos prejudiciais à saúde humana, não o torna um completo substitutivo do RPT. Visto que o teste é baseado no sistema de defesa do artrópode, não provê resultados tão relevantes aos humanos quanto o MAT. Apesar de atualmente - LAL ser responsável por mais de $90 \%$ dos testes de pirogênio ${ }^{2}$, ainda sim, algumas classes de produtos não são compatíveis com o método como, medicamentos que interferem com o sistema de coagulação do artrópode mascarando a detecção do LPS na amostra ou aqueles que apresentam características organolépticas que não são compatíveis com o sistema de leitura do teste (Tabela 1).

Assim, o MAT foi desenvolvido para contornar as limitações dos ensaios com animais no RPT e aumentar a margem de segurança apresentada pela utilização do teste LAL no controle de parenterais, ampliando o espectro de detecção de moléculas com potencial pirogênico. Fazendo um paralelo com o primeiro ensaio in vitro desenvolvido para a detecção de LPS, o LAL (in vitro de primeira geração), o MAT é um método alternativo in vitro de segunda geração devido ao seu refinamento metodológico, por diferir na origem da matriz que responde a um potencial pirogênico (células humanas), fazer uso de controles positivos e negativos, detectar uma maior variedade de pirogênios não-LPS e conferir aplicabilidade a maior gama de produtos (Hartung, 2015). A nova abordagem pela utilização de material humano contribui para uma maior confiabilidade da resposta in vitro do MAT por ser uma metodologia baseada na resposta imune aos pirogênios correspondendo à condição

Tabela 1- Comparação entre métodos de detecção de pirogênios.

\begin{tabular}{|c|c|c|c|}
\hline $\begin{array}{c}\text { Teste de } \\
\text { pirogenicidade }\end{array}$ & $\begin{array}{c}\text { In vivo } \\
\text { Teste de Pirogênio em coelhos (RPT) }\end{array}$ & $\begin{array}{c}1^{\mathrm{a}} \text { geração in vitro } \\
\text { Lisado de Amebócitos de Limulus (LAL) }\end{array}$ & $\begin{array}{c}2^{\text {a }} \text { geração in vitro } \\
\text { Teste de ativação de monócitos (MAT) }\end{array}$ \\
\hline Sistema teste & - Coelhos & - Hemolinfa de caranguejo-ferradura & - Células monocíticas humanas \\
\hline Especificidade & -Todos os pirogênios & - Endotoxina & - Todos os pirogênios \\
\hline $\begin{array}{l}\text { Limite de } \\
\text { detecção }\end{array}$ & $-5 \mathrm{UE} / \mathrm{mL}$ & - 0,03-0,005 UE/mL & - 0,03 UE/mL \\
\hline Tipo do teste & -Teste limite & - Teste limite/quantitativo & - Teste limite/quantitativo \\
\hline Aplicações & $\begin{array}{l}\text { - Produtos farmacêuticos } \\
\text { - Produtos biológicos } \\
\text { - Dispositivos médicos (extrato) }\end{array}$ & $\begin{array}{l}\text { - Produtos farmacêuticos } \\
\text { - Produtos biológicos (limitado) } \\
\text { - Dispositivos médicos (extrato) } \\
\text { - Ar e poeira (limitado) }\end{array}$ & $\begin{array}{l}\text { - Produtos farmacêuticos } \\
\text { - Produtos biológicos } \\
\text { - Dispositivos médicos (extrato/diluição) } \\
\text { - Produtos derivados do sangue } \\
\text { - Ar e poeira }\end{array}$ \\
\hline Vantagens & $\begin{array}{l}\text { - Detecta todos os pirogênios } \\
\text { - Padrão ouro dos ensaios de } \\
\text { pirogênios }\end{array}$ & $\begin{array}{l}\text { - Rápido } \\
\text { - Fácil execução } \\
\text { - Redução do prazo de análises }\end{array}$ & $\begin{array}{l}\text { - Detecta todos os pirogênios } \\
\text { - Rápido } \\
\text { - Fácil execução } \\
\text { - Redução do prazo de análises } \\
\text { - Aplicável a todos os produtos }\end{array}$ \\
\hline Desvantagens & $\begin{array}{l}\text { - Variabilidade biológica } \\
\text { - Não aplicável a todos os produtos } \\
\text { - Alto custo de manutenção dos } \\
\text { animais } \\
\text { - Questões éticas }\end{array}$ & $\begin{array}{l}\text { - Detecta somente endotoxinas } \\
\text { - Não aplicável a todos os produtos } \\
\text { - Não detecta endotoxinas ligadas } \\
\text { - Questões éticas }\end{array}$ & $\begin{array}{l}\text { - Necessidade de validação para produtos } \\
\text { não contemplados na validação do método. } \\
\text { - Qualificação das matrizes celulares }\end{array}$ \\
\hline $\begin{array}{l}\text { Aceitação } \\
\text { regulatória }\end{array}$ & $\begin{array}{l}\text { - Principais farmacopeias (FB, USP, } \\
\text { FE, JP, IP, BP) }\end{array}$ & $\begin{array}{l}\text { - Principais farmacopeias } \\
\text { (FB, USP, FE, JP, IP, BP) }\end{array}$ & - Aceitação na FE e FDA \\
\hline Custo* & - \$475-\$990 & $-\$ 85-\$ 160$ & $\begin{array}{l}\text { - } \$ 83-\$ 100 \text { (baseado no kit comercial } \\
\text { Endosafe-IPT, podendo ser mais barato } \\
\text { sem utilização do kit) }\end{array}$ \\
\hline
\end{tabular}

EU: unidades de endotoxina, FB: Farmacopeia Brasileira, USP: Farmacopeia dos Estados Unidos, FE: Farmacopeia Europeia, JP: Farmacopeia Japonesa, IP: Farmacopeia Indiana, BP: Farmacopeia Britânica, FDA: FoodandDrugAdministration.

* Dados retirados do Costs of Animal and Non-Animal Testing Humane Society International

${ }^{* *}$ Adotado e modificado de Melandriet al. 2010. 
humana, excluindo os riscos inerentes à extrapolação interespécies presentes no LAL e RPT (Tabela 1).

Em uma comparação direta com o RPT (Tabela 1), o MAT apresenta redução de custos, tempo de processamento e fornece o mesmo nível de segurança para os produtos. No que diz respeito à sensibilidade, o MAT é superior ao RPT, além de ser uma avaliação quantitativa de pirogênios, facilitando a determinação exata do teor de pirogênio numa amostra. Como - MAT detecta outros pirogênios não endotoxina, os resultados são apresentados como unidades equivalentes de endotoxina por $\mathrm{mL}$ (UEE/mL) (Montag et al., 2007). A quantidade de pirogênio é relacionada com o nível de liberação da citocina que é calculado a partir dos valores de densidade óptica medidos pelo ensaio de ELISA e referindo-se a concentrações de um padrão internacional de endotoxina. O MAT ainda permite uma diferenciação entre os efeitos de fatores de pirogênios e de interferência, visto que determinados produtos podem induzir o aumento ou inibição sobre a liberação de citocinas e outros mediadores da resposta pirogênica, o que não é distinguível nos ensaios RPT e LAL (Yum et al., 2010; Ishiguro et al., 2007; Brent, 2001).
A técnica do MAT apresenta outras vantagens frente ao LAL e RPT que é a maior abrangência de classes de produtos passíveis de análise, tais como biofármacos, soros hiperimunes, vacinas e contaminação do ar (Kindinger et al., 2005). Além disso, existe a possibilidade de adaptações no ensaio convencional (Whole Blood Test, WBT) que permitem avaliar superfícies e drogas que interfiram com o teste. Assim, foi desenvolvido 0 teste AWIPT (Absorb and Wash In vitro Pyrogen Test) que é uma adaptação que traz maior sensibilidade e menor interferência com relação aos outros testes de avaliação de pirogênio e o MAT convencional, pois as endotoxinas são extraídas com esferas ligadoras de endotoxina, que após lavagens retiram os materiais interferentes do WBT. Esta modificação faz com que o MAT possa ser utilizado em superfícies sólidas como os dispositivos médicos e com drogas imunomodulatórias e tóxicas (Daneshian et al., 2006). É óbvio que as modificações da configuração e leitura do MAT permitirão ampliar a sua utilização para quantificar e diferenciar a atividade de numerosas substâncias imuno-reguladoras que afetam a infecção e inflamação.

Tabela 2- Variantes dos sistemas do ensaio MAT.

\begin{tabular}{|c|c|c|c|}
\hline Testes & Sistemas & Leitura & Fonte \\
\hline WBT/IL-1 $\beta^{*}$ & Sangue Total Humano & Interleucina-1 $\beta$ & ICCVAM, 2008 \\
\hline Cryo WBT/IL-1 $\beta$ * & Sangue Total Humano Criopreservado & Interleucina-1 $\beta$ & ICCVAM, 2008 \\
\hline WBT/IL-6* & Sangue Total Humano & Interleucina-6 & ICCVAM, 2008 \\
\hline PBMC/IL-6* & $\begin{array}{l}\text { Células Mononucleares do Sangue } \\
\text { Periférico }\end{array}$ & Interleucina-6 & ICCVAM, 2008 \\
\hline MM6/IL-6* & $\begin{array}{l}\text { Linhagem Celular Monocítica } \\
\text { Monomac-6 (MONOMAC-6) }\end{array}$ & Interleucina-6 & ICCVAM, 2008 \\
\hline THP-1/TNF- $\alpha$ & Linhagem celular THP-1 & Fator de necrose tumoral alfa & Eperon e Jungi, 1996. \\
\hline THP-1/neopterin & Linhagem celular THP-1 & Neopterin & $\begin{array}{c}\text { Werner-Felmayeret al., 1995; Peterbauer and } \\
\text { Werner-Felmayer, } 1999 .\end{array}$ \\
\hline MM6/TNF- $\alpha$ & $\begin{array}{l}\text { Linhagem Celular Monocítica } \\
\text { MONOMAC-6 }\end{array}$ & Fator de necrose tumoral alfa & Poole et al., 1988; Ziegler-Heitbrocket al., 1988. \\
\hline PBMC/IL-1 $\beta$ & $\begin{array}{l}\text { Células Mononucleares do Sangue } \\
\text { Periférico }\end{array}$ & Interleucina-1 $\beta$ & Hansen, 1990; Christensen, 1990 \\
\hline bWBT/PGE 2 & Sangue Total Bovino & Prostaglandina $\mathrm{E}_{2}$ & Wunderlichet al., 2014 \\
\hline rWBT/ PGE 2 & Sangue Total de Coelho & Prostaglandina $\mathrm{E}_{2}$ & Ochaiet al., 2003 \\
\hline rWBT/IL- $1 \beta$ & Sangue Total de Coelho & Interleucina-1 $\beta$ & Schindler, 2003 \\
\hline rWBT/ IL- 8 & Sangue Total de Coelho & Interleucina-8 & Schindler, 2003 \\
\hline rWBT/ IL- 6 & PBMC isolado de filtros linfocitários & Interleucina-6 & Koryakinaet al., 2014 \\
\hline
\end{tabular}




\section{MATRIZES CELULARES UTILIZADAS NOS TESTES DO PIROGÊNIO}

Todos os ensaios de pirogênio se resumem no contato do pirogênio com uma matriz celular e seu produto. Esta etapa é o que torna 0 ensaio de pirogênio crítico, quando utilizamos matrizes, como no RPT e LAL. Atualmente, estima-se o uso de mais de 400 mil coelhos e aproximadamente 30 mil caranguejos por ano, destinados aos ensaios de pirogênio e endotoxina nos setores de fármacos e produtos biológicos (Hartung, 2015). Com relação ao LAL, apesar de - Limulus ser mantido vivo durante o processo de punção da hemolinfa e ser devolvido ao mar, é importante destacar que aproximadamente $20 \%$ dos animais não sobrevivem a este procedimento (Rudloe e Hernkind, 1983; Walls e Berkson, 2003).

Com isto, o MAT foi baseado na reação febril humana frente a um determinado pirogênio. Se existir a contaminação pirogênica, um pirogênio endógeno é liberado, como citocinas, que podem ser quantificados por ELISA, sendo esta uma quantificação indireta da contaminação. A quantificação dos efeitos pirogênicos pode ser realizada pelas leituras de interleucina (IL)-1 $\beta$, IL-6, TNF- $\alpha$, IL-8, nitrito, neopterin e prostaglandina $E_{2} \quad\left(P G E_{2}\right)$, sendo oficialmente aceita pela FE a determinação da indução de IL-1ß, IL-6 (Tabela 2).

Apesar das vantagens do MAT, restrições práticas e regulatórias relacionadas ao uso de sangue fresco ou monócitos associados à flebotomia, exclusão de doadores hipo ou hiperresponsivos e avaliação prévia de agentes infecciosos são fatores relevantes para a implantação do teste. Assim, várias alternativas vêm sendo estudadas com o intuito de otimizar o ensaio e torná-lo aplicável em larga escala, i.e. passível de uso, por exemplo, nas indústrias farmacêuticas e biotecnológicas. Como alternativas ao uso de sangue fresco foram validadas o uso de sangue criopreservado e células da linhagem monocítica (MONOMAC-6) no MAT (Tabela 2). $\mathrm{Na}$ literatura outras abordagens de sistemas celulares foram descritas como doadoras de células monocíticas, como o uso de sangue de coelho e sangue bovino (Tabela 2). No entanto, estas abordagens se distanciam do princípio dos 3R's, uma vez que mantém a utilização de outros animais, além de manterem a limitação da extrapolação interespécies dos ensaios oficias (RPT e LAL), reduzindo a confiabilidade da resposta. Outras fontes alternativas para 0 aperfeiçoamento do MAT incluem o uso de linhagens celulares (ex. THP-1 e subclones MONOMAC-6), que apresentaram alta variabilidade e células mononucleares do sangue periférico (Peripheral blood mononuclear cell-PBMC) criopreservadas purificadas de filtros linfocitários, tratados como bio-resíduo em hospitais e centros de doação de sangue, por não serem utilizados no arsenal terapêutico (Tabela 2).

A vantagem da criopreservação para a logística funcional do MAT em escala industrial se deve à possibilidade de fornecimento constante de sangue no laboratório, pre-testado para possíveis patógenos. A padronização da criopreservação também permitiu o desenvolvimento de kits comerciais para utilização do MAT (Pyrocheck, Endosafe IPT, Pyrodetect), facilitando o processo de aquisição e validação do sangue (Hartung, 2015).

\section{AVALIAÇÃO DE PIROGÊNIOS EM PRODUTOS BIOLÓGICOS}

Dentro das várias áreas de aplicação do conceito dos 3R's, o controle da qualidade de produtos biológicos torna-se alvo prioritário na redução do uso de animais devido à demanda dos ensaios de rotina para liberação lote-alote antes da comercialização, o que leva a uma grande utilização de animais nos ensaios de qualidade e segurança. Dentre os ensaios exigidos para garantir a qualidade dos sistemas e controle dos processos conforme as Boas Práticas de Fabricação (BPF), as autoridades regulatórias preconizam o ensaio de detecção de pirogênios em produtos e manufaturados.

O teste de pirogênios é mandatório para produtos farmacêuticos, biotecnológicos e dispositivos médicos com o propósito de uso médico e veterinário para assegurar a ausência de microrganismos e seus metabólitos com potencias pirogênicos em soluções intravenosas durante o processo de produção. Rapidamente as indústrias farmacêutica e biotecnológica aumentaram o número de lançamentos de medicamentos novos e consequentemente, a demanda de ensaios de controle da qualidade exigidos, conforme regulamentações. Atualmente, acompanhando o crescimento do mercado, o teste de pirogênio está avaliado em \$462 
milhões dólares americanos em 2014, podendo chegar a $\$ 823$ milhões em 2019, sendo $80 \%$ deste mercado destinado ao $\mathrm{LAL}^{2}$. Entretanto, o crescente aumento na indústria de biotecnologia e a complexa formulação desse setor são fatores-chaves para os investimentos, sendo uma tendência global o desenvolvimento de métodos alternativos in vitro com maior potencial tecnológico de detecção de potenciais pirogênios. As receitas do segmento de biotecnologia mundial são projetadas para crescer a uma taxa anual de $9 \%$ durante os cinco anos a 2019, alcançando \$444 milhões dólares americanos ${ }^{3}$. Estes valores per se justificam o investimento científico e financeiro em métodos alternativos que substituam por completo os ensaios com animais, principalmente na indústria de biotecnológicos, devido a particularidades inerentes a esta classe de produtos.

A detecção de pirogênios em produtos biológicos mantem-se uma questão crítica na produção e controle destes e requer teste com extrema sensibilidade. Embora todas as bactérias tenham alguma associação com endotoxina, a mais potente fonte pirogênica é de origem de bactérias Gram-negativas. Assim, do ponto de vista regulatório, o LAL foi regulamentado como teste oficial para detecção de endotoxina, sendo substitutivo quando possível ao RPT Conforme recomendado pela USP "o teste de pirogênio em coelhos deve ser testado somente se o produto é incompatível com o teste de LAL", já que a reação envolve enzimas que podem ser afetadas por vários fatores inerentes ao produto biológico (Tabela 3).

Além da contaminação exógena, na indústria de biotecnologia, bactérias Gramnegativas são amplamente utilizadas na elaboração de produtos provenientes da tecnologia de DNA recombinante, tais como os peptideos e proteínas, sendo estes contaminados com endotoxinas (Magalhães et al., 2007). Por esta razão, processos diferentes (resinas de afinidade com LPS, extrações em duas fases, ultrafiltração, cromatografia de interação hidrofóbica, cromatografia de troca iônica e adsorventes de membrana) têm sido desenvolvidos para a remoção de LPS destes biotecnológicos, baseados nas propriedades únicas das moléculas de endotoxina.

Uma análise dos produtos derivados do sangue (albumina humana), combinando um inibidor de LPS (polimixina B) e MAT, demonstrou que a contaminação pirogênica dos lotes eram predominantemente endotoxinas ao invés de outros tipos de pirogênios (Perdomo-Morales, 2011). Entretanto, substâncias pirogênicas oriundas de outros microrganismos (bactérias Grampositivos, exotoxinas ou constituintes da parede celular), obviamente existem, causando sintomatologia, como estado febril grave e doenças sépticas, muitas vezes indistinguíveis de infecções por bactérias Gram-negativas.

\begin{tabular}{|c|c|c|c|c|c|}
\hline Produto biológico & Origem & Interferente & Resultado & Mecanismo de Ação & Limitação \\
\hline Vacinas & $\begin{array}{l}\text { Formulação } \\
\text { (adjuvante) }\end{array}$ & $\begin{array}{l}\mathrm{Al}(\mathrm{OH})_{3 .} \\
\text { Ex. Vacina DTaP, Hepatite B }\end{array}$ & Falso - & Liga a endotoxina & LAL \\
\hline Vacinas & $\begin{array}{l}\text { Produto de } \\
\text { purificação }\end{array}$ & $\beta$-Glucana & Falso + & Mimetiza a endotoxina & LAL \\
\hline $\begin{array}{l}\text { Vacinas e } \\
\text { imunobiológicos }\end{array}$ & Formulações & EDTA, citrato, inibidores de protease & Falso & Inibição das enzimas & LAL \\
\hline $\begin{array}{l}\text { Vacinas e } \\
\text { imunobiológicos }\end{array}$ & Formulações & $\begin{array}{l}\text { Elevado conteúdo de proteínas (Ex. } \\
\text { Albumina, soro hiperimune) }\end{array}$ & Falso- & Liga ao LPS & LAL \\
\hline $\begin{array}{l}\text { Imunobiológicos e } \\
\text { vacinas }\end{array}$ & & & & Turbidez e cor & LAL \\
\hline Imunobiológicos & Príncipio ativo & Imunoglobulinas (ex.Pentaglobulin) & Falso + & Induz reação imunológica & RPT/LAL \\
\hline Vacinas & Príncipio ativo & $\begin{array}{l}\text { Vírus que induzem febre (Ex. vacina } \\
\text { contra Influenza) }\end{array}$ & Falso + & Induz mecanismo de febre & RPT \\
\hline Imunobiológicos & Príncipio ativo & IFN & Falso + & Indução de citocinas & MAT \\
\hline $\begin{array}{l}\text { Vacinas e } \\
\text { Imunobiológicos }\end{array}$ & $\begin{array}{l}\text { Príncipio ativo e } \\
\text { formulações }\end{array}$ & Agentes citotóxicos & Falso - & Morte celular & MAT \\
\hline
\end{tabular}

Falso negativo (-): resultados que apesar da presença do pirogênio, não foi possível detectá-lo, Falso +: resultados que na prática não detectaram o pirogênio, apesar da presença do pirogênio, não foi possível detectá-lo. 
As bactérias Gram-positivas merecem atenção especial nos processos de fabricação de biotecnológicos, visto que várias etapas são geralmente contaminadas por espécies ambientais (Schindler et al., 2009). O significado clínico do pirogênio não-endotoxina é provavelmente subestimada, já que sua presença não é normalmente esperada, contribuindo para uma grave subnotificação que poderia ser antecipada com o adequado controle da qualidade.

Como descrito anteriormente, alguns produtos possuem características que interferem nos testes de pirogênios, RPT e LAL. Dentre estes, podemos destacar os produtos biológicos que apresentam peculiaridades devido sua complexidade estrutural e funcional, sendo uma classe de produtos que merece atenção especial, de modo a evitar problemas de interpretação de resultados. Amostras biológicas problemáticas no RPT são aquelas que influenciam os mecanismos centrais ou periféricos da regulação da temperatura corporal (ex. vacina Influenza) (Grossgebauer, 1971), impedindo a avaliação da febre em coelhos. O mesmo aplica-se a medicamentos que podem causar reações imunológicas (imunoglobulinas - ex. IgG intravenosa) (Huszár et al., 2002) e suspensões oleosas ou detergentes (Hasiwa et al., 2013). Além disso, o ensaio RPT não pode ser usado para as preparações celulares, tais como elementos figurados e células tronco (Hartung et al., 2001) Drogas que interferem com o sistema de coagulação do teste $L A L$, através da inibição gerando resultado falsonegativo (ligação de cátions divalentes- EDTA/ citrato $e$ inibidores da protease) ou pela indução com resultado falso-positivo (alto teor de proteína, as proteases), não podem ser testadas por este sistema (Dawson, 2005). Polissacarídeos podem ser contaminantes obtidos do processo de purificação e derivados de materiais de filtro de celulose, podendo originar resultados falso-positivos (Henne et al., 1984). Além disso, uma série de componentes de ligação de endotoxinas a partir de plasma é conhecida por mascarar o ensaio de LAL (Dawson, 2005), assim como, características organolépticas do produto, como a turbidez e cor, podem perturbar os princípios de medição. Devido a estas interferências com o sistema de teste, muitos produtos devem ser diluídos, respeitando a sua máxima diluição válida. Os principais problemas relacionados a interferentes e MAT são substâncias que interagem com os monócitos (ex. IL-1, antagonistas do receptor de soluções não fisiológicas, agentes citotóxicos, as proteínas recombinantes com atividade de citocina, tais como IFN-ץ), sendo estes produtos não susceptíveis a avaliação por esta metodologia (Martinez e Coleman, 1989).

Em especial, vacinas apresentam interferentes particulares e inerentes de sua constituição como (1) as derivadas de bactérias Gram-negativas, tendo o LPS como componente (Knight e Lucken, 1977; Tsai et al., 1989), (2) algumas vacinas virais que contêm componentes inerentemente pirogênicos (Nyerges e Jaszovszky, 1981), (3) hidróxido de alumínio $\left[\mathrm{Al}(\mathrm{OH})_{3}\right]$, substância interferente do LAL, sendo necessário o teste em coelhos (Park et al., 2005) e (4) multicomponentes, com interação entre as substâncias (Carlin e Viitanen, 2003).

Os produtos derivados do sangue (hemoderivados) também merecem atenção especial, uma vez que, apresenta uma forte interferência com o teste LAL, sendo 0 RPT o teste mais indicado (Hartung et al., 2001). A revisão das monografias da FE para produtos derivados do plasma (ex. albumina humana, imunoglobulina humana normal, imunoglobulina humana para administração intravenosa e fator VIII da coagulação humana) incentiva a utilização de métodos alternativos ao RPT. Porém existem as particularidades, uma vez que existem alguns produtos que causam reações em coelhos (imunoglobulinaslgG intravenosa) (Huszár et al., 2002) não sendo esta metodologia adequada, enquanto o LAL pode ser adaptado para alguns produtos de sangue se for utilizada uma diluição adequada, respeitando a máxima diluição válida do produto. Porém, ainda existem interferentes comuns ao RPT e LAL, como as $\beta$-glucanas, que podem tanto mascarar a pirogenicidade do LPS no RPT (falso negativo/-) (Pardo-Ruiz et al., 2015), bem como induzir uma positividade no LAL, mesmo na ausência do LPS (falso positivo/+) (Cooper et al., 1997). Alguns dos interferentes envolvidos na detecção de pirogênio pelos vários sistemas de análise utilizados no controle da qualidade de produtos biológicos encontram-se exemplificados na Tabela 3.

Tendo em vista os pontos abordados, o MAT é um substituto potencial para o teste de pirogênios em muitos produtos biológicos, 
porém, até o momento o seu uso foi validado apenas para alguns medicamentos, o que levou as agências regulatórias a exigirem a validação da aplicabilidade do teste por produto. Devido à falta de informação sobre a plena aplicabilidade do MAT, principalmente em produtos biológicos, o RPT na FB ainda é amplamente utilizado e preconizado para a maioria destes produtos de uso parenteral, conforme revisado por Caldeira e colaboradores (Caldeira et al., 2015). O trabalho faz um diagnóstico dos principais produtos de interesse nacional e avalia as monografias dos produtos injetáveis fornecendo um banco de dados que norteia estudos sobre a aplicabilidade do MAT para produtos não contemplados no processo de validação. Apesar do grande número de biológicos exigirem exclusivamente 0 ensaio de RPT conforme preconizado pela FB, outras farmacopeias também orientam realizar 0 RPT em imunobiológicos não contemplados na FB (ex. vacina pneumocócica e seus polissacarídeos constituintes), somando ao percentual de ensaios in vivo contabilizados pelos autores. Em contrapartida, outras vacinas de importância nacional e incluídas no Programa Nacional de Imunização e Biofármacos (ex. eritropoietina, alfainterferon) são avalidas pelo teste de endotoxina (LAL) conforme preconizado por farmacopeias internacionais, o que remete a um maior número de ensaios in vitro em imunobiológicos, além dos incluídos na FB.

Adicionalmente, todo produto originário de inovação biotecnológica deve ser avaliado pelo teste de pirogenicidade RPT, porém a FE ressalta e recomenda que todos os novos produtos para administração parenteral devam ser testados pelo MAT, reforçando a nova conduta de substituição de animais como padrão ouro e acompanhando a tendência mundial do desenvolvimento de biotecnológicos.

\section{CONCLUSÃO}

Neste artigo foram abordadas as oportunidades e lacunas para a aceitação do MAT como substituto ao uso de animais nos ensaios de pirogênio. As oportunidades destacam-se, principalmente em produtos biológicos, devido à complexidade e alto valor agregado, o que torna a validação produtoespecífico mais rigorosa frente ao teste. Os argumentos pautados reforçam a necessidade do investimento financeiro e suporte de dados técnico-científicos, de modo, a acelerar a aprovação desta metodologia alternativa para o uso de animais em escala industrial, incorporando o MAT em produtos testados em animais ou descobertos pelas metodologias atuais antecipando assim, os possíveis riscos que estes produtos possam trazer à saúde humana.

\section{AGRADECIMENTOS}

Ao Programa de Pós-graduação em Vigilância Sanitária do INCQS/Fiocruz ressaltando que este trabalho faz parte da dissertação de mestrado de Elaine Cristina Azevedo Navega. Isabella Delgado é bolsista de produtividade do CNPq.

\section{REFERÊNCIAS}

ADVISORY GROUP ON ALTERNATIVES TO ANIMAL TESTING IN IMMUNOBIOLOGICALS. THE TARGET ANIMAL SAFETY TEST--IS IT STILL RELEVANT? Biologicals, v. 30, n. 4, p. 277-287, 2002.

BRENT, J. Current management of ethylene glycol poisoning. Drugs, v. 61, n. 7, p. 979-988, 2001.

CALDEIRA, C.; CRUZ, M.; FREITAS, J. et al. Aplicabilidade do Teste de Ativação de Monócitos (MAT) no Brasil: importância da sua utilização como teste para detecção de pirogênios no controle da qualidade de produtos injetáveis. Visa em Debate, v. 3, n. 3, p. 41-46, 2015.

CARLIN, G.; VIITANEN, E. In vitro pyrogenicity of a multivalent vaccine: Infanrix. Pharmeuropa, v. 15, n. 3, p. 418-423, 2003.

DANESHIAN, M.; GUENTHER, A.; WENDEL, A., HARTUNG, T.; von AULOCK, S. In vitro pyrogen test for toxic or immunomodulatory drugs. Journal of Immunological Methods. v. 313, n. 1-2, p. 169175, 2006.

DAWSON, M.E. LAL Technical Report. Interference with the LAL Test and How to Address It, LAL Update, v. 22, p. 1-6, 2005.

EPERON, S.; JUNGI, T.W. The use of human monocytoid lines as indicators of endotoxin. Journal of Immunological Methods, v. 194, n. 2, p. 121-129, 1996.

EUROPEAN PHARMACOPOEIA. Monocyte Activation Test. In Ph. Eur. 7th Edition, Chapter 2.6.30. 2010. Disponivel em http://www.edqm.eu/en/edqmhomepage-628.html. Acessado em: 12/10/2014.

GAINES DAS, R.E.; BRUGGER, P.; PATEL, M. et al. Monocyte activation test for pro-inflammatory and pyrogenic contaminants of parenteral drugs: test design and data analysis. Journal of Immunology Methods, v. 288, n.1-2, p. 165-177, 2004. 
GROSSGEBAUER, K. Hypersensitivity to influenza virus preparations, vaccines, and egg proteins measured in rabbit pyrogen test. Archiv für die gesamte Virusforschung, v. 35, n.4, p. 339-348, 1971.

GRANT, R. Emotional hypothermia in rabbits. American Journal of Physiology, v. 160, n. 2, p. 285290, 1950

HANSEN, E.W.; CHRISTENSEN, J.D. Comparison of cultured human mononuclear cells, Limulus amebocyte lysate and rabbits in the detection of pyrogens. Journal of Clinical Pharmacy and Therapeutics, v. 15, n. 6, p. 425-33,1990.

HARTUNG, T. The human whole blood pyrogen test lessons learned in twenty years. ALTEX, v. 32, n. 2, p. 79-100, 2015

HARTUNG, T.; AABERGE, I.; BERTHOLD, S. et al. Novel pyrogen tests based on the human fever reaction. ATLA, v. 29, p. 99-123, 2001.

HENNE W, SCHULZE H, PELGER M, et al. Hollowfiber dialyzers and their pyrogenicity testing by Limulus amebocyte lysate. Artificial Organs, v.8, n. 3, p. 299305, 1984.

HUSZÁR, G.; JENEI, B.; SZABÓ, G. et al. Detection of pyrogens in intravenous IgG preparations. Biologicals, v. 30, n. 2 , p. $77-83,2002$.

ICCVAM. Validation status of five in vitro test methods proposed for assessing potential pyrogenicity of pharmaceuticals and other products. ICCVAM test method evaluation report. Disponível em: http://iccvam. niehs.nih.gov/methods/pyrogen/pyr tmer.htm. Acessado em: 10/10/2014.

ISHIGURO, T.; YASUI, M.; NAKADE, Y. et al. Extrinsic allergic alveolitis with eosinophil infiltration induced by 1,1,1,2-tetrafluoroethane (HFC-134a): a case report. Internal Medicine, v. 46, n.17, p. 1455-1457, 2007.

KNIGHT, P.A.; LUCKEN, R.N. Studies on the toxicity of a variety of human vaccines as measured by laboratory tests. Developments in Biological Standardisation, v. 34, p. 181-187, 1977.

KORYAKINA, A.; Frey, E.; Bruegger, P. Cryopreservation of human monocytes for pharmacopeial monocyte activation test. Journal of Immunological Methods, v. 405, p. 181-191, 2014.

MARTINEZ, F.; COLEMAN, J.W. The effects of selected drugs, including chlorpromazine and nonsteroidal anti-inflammatory agents, on polyclonal lgG synthesis and interleukin 1 production by human peripheral blood mononuclear cells in vitro. Clinical and Experimental Immunology, v. 76, n. 2, p. 252257, 1989

MAGALHÂES, P.O., LOPES,A.M., MAZZOLA,P.G. et al. 2007. Methods of endotoxin removal from biological preparations: a review. Journal of Pharmacy \& Pharmaceutical Sciences. v. 10, n. 3, p. 271-287.

MCCLOSKY, W.T.; PRICE, W.T.; VAN WINKLE, W.J. et al. Results of the first USP collaborative study of pyrogens. Journal of the American Pharmacists Association, v. 32, n. 3, p. 69-73, 1943.

MELANDRI, V.C.R.; FARIA, G.C.; CALDEIRA, C. et al. Utilização de métodos alternativos na determinação da contaminação pirogênica no controle de produtos injetáveis sujeitos à vigilância sanitária. Universitas: Ciências da Saúde, v. 8, n. 2, p. 69-95, 2010.

NYERGES, G., JASZOVSZKY, I. Reliability of the rabbit pyrogen test and of the limulus test in predicting the pyrogenicity of vaccines in man. Acta microbiologica Academiae Scientiarum Hungaricae, v. 28, n. 3, p. 235-243, 1981.

OCHIAI, M.; YAMAMOTO, A.; KATAOKA, M. et al. Interfering effect of diphtheria et na use acellular pertussis combined (DTaP). Vaccines on the bacterial endotoxin test. Biologicals, v. 29, n.1, p. 55 - 58, 2001.

PARK, C.Y.; JUNG, S.H.; BAK, J.P. et al. Comparison of the rabbit pyrogen test and Limulus amoebocyte lysate ( $L A L)$ assay for endotoxin in hepatitis $B$ vaccines and the effect of aluminum hydroxide. Biologicals, v. 33, n. 3, p. 145-151, 2005.

PERDOMO-MORALES, R.; PARDO-RUIZ, Z.; SPREITZER, I. et al. Monocyte activation test (MAT) reliably detects pyrogens in parenteral formulations of human serum albumin, ALTEX, v. 28, n. 3, p. 227-35, 2011.

PÖBETANECKER, A.; CUBETALER, K. Evaluation of the relevance of the target animal safety test for the quality control of veterinary immunological medicinal products. ALTEX, v. 15, n. 5, p. 71-75, 1998.

POOLE, S.; GAINES DAS, R.E. Towards a 'human pyrogen test'. European Journal of Parenteral Sciences, v. 6, Special no, p.63-64, 2001.

POOLE, S.; THORPE, R.; MEAGER, A. et al. Detection of pyrogen by cytokine release. Lancet, v. 1, n. 8577, p. 130, 1998.

PRESGRAVE, O., MOURA, W., CALDEIRA, C., DELGADO, I.The role of the brazilian center for validation of alternative methods (BRACVAM) in the process of validation in Brazil: looking to the future. Journal Pharmacy Pharmacognosy Research, v. 2, n. 1: s38, 2014.

RUDLOE, A.; HERNKIND, A. E. The effect of heavy bleeding on mortality of the horseshoe crab, Limulus polyphemus, in the natural environment. Journal of Invertebrate Pathology, v. 42, n. 2, p. 167-176, 1983.

RUSSEL, W.M.S.; BURCH, R.L. The Principles of Humane Experimental Technique. Methuen, London, 1959.

SCHINDLER, S.; BRISTOW, A.; CARTMELL, T. et al. Comparison of the reactivity of human and rabbit blood towards pyrogenic stimuli. ALTEX, v. 20, n. 2, p. 59-63, 2003.

TSAI, C.M.; FRASCH, C.E.; RIVERA, E. et al. Measurements of lipopolysaccharide (endotoxin) in meningococcal protein and polysaccharide 
preparations for vaccine usage. Journal of Biological Standardisation, v.17, n.3, p. 249-258, 1989.

WALLS, E. A.; BERKSON, J. Effects of blood extraction on horseshoe crabs (Limulus polyphemus). Fish Bull, v. 101, n. 2, p. 457-459, 2003.

WELSH, H.; CALVERY, H.O.; MCCLOSKY W.T. et al. Method of Preparation and Test for Bacterial Pyrogen. Journal of the American Pharmacists Association, v. 32, n. 3, p. 65-69, 1943.

WERNER-FELMAYER, G.; BAIER-BITTERLICH, G.; FUCHS. et al. Detection of bacterial pyrogens on the basis of their effects on gamma interferon-mediated formation of neopterin or nitrite incultured monocyte cell lines. Clinical and Diagnostic Laboratory Immunology, v. 2, n. 3, p. 307-313, 1995.

WUNDERLICH, C.; SCHUMACHER, S.; KIETZMANN, M. Pyrogen detection methods: comparison of bovine whole blood assay (bWBA) and monocyte activation test (MAT). BMC Pharmacology and Toxicology, v. 15, n. 50., 2014. Disponível em: http://www.biomedcentral.com/2050-6511/15/5.

Acesso em: 13/03/2015.

YUM, S.; WOO, S.; KAGAMI, Y. et al. Changes in gene expression profile of medaka with acute toxicity of Arochlor 1260, a polychlorinated biphenyl mixture. Comparative Biochemistry and Physiology Part C: Toxicology \& Pharmacology, v. 151, n. 1, p. 51-56, 2010.

HOFFMANN, S.; Peterbauer, A.; Schindler, S.; et al. International Validation of novel pyrogen tests based on human monocytoid cells. Journal of Immunological Methods, v. 298, n. 1-2, p.161-173, 2005.

SCHINDLER, S.; SPREITZER, I.; LÖSCHNER, B.; et al. International validation of pyrogen tests based on cryopreserved human primary blood cells. Journal of Immunological Methods, v. 316, n. 1-2, p. 42-51, 2006.

HERMANN, C.; SPREITZER, I.; SCHRÖDER, N. W. $\mathrm{J}$; et al. Cytokine induction by purified lipoteichoic acids from various bacterial species - role of LBP, sCD14, CD14 and failure to induce interleukin 12 and subsequent interferon $\mathrm{g}$ release. European Journal of Immunology. v. 32, n.2, p. 541-551, 2001.

HASIWA, N.; DANESHIAN, M.; BRUEGGER, P.; et al. Evidence for the detection of non-endotoxin pyrogens by the whole blood monocyte activation test. ALTEX, v. 30, n. 2, p. 169-208, 2013.

WILLIAMS, L.K. In: Endotoxin: pyrogens, LAL testing and depyrogenization. 2 ed. New York: Marcel Dekker, 2007.

BRASIL. Resolução normativa número 18. Diário Oficial da União, 25 de dezembro de 2014.

ASHTON, R.; DE WEVER; B., FUCHS, H. W. et al. Roggen State of the art on alternative methods to animal testing from an industrial point of view: ready for regulation?1. ALTEX, v. 31, n. 3, p. 357-363, 2014.
DU,Y; LI, X.J.; TAN, D.J. Comparison of temperature rise interpretations in the rabbit pyrogen test among Chinese, Japanese, EUROPEAN, AND UNITED STATES PHARMACOPEIAS AND 2-2-2 THEORETICAL MODELS PROPOSED BY S. HOFFMANN. Innate Immunology. v. 17, n. 5, p. 486495. doi: 10.1177/1753425910384754. 2011.

ICCVAM. Introduction and Rationale for the Proposed Use of In vitro Pyrogen Test Methods. ICCVAM In vitro Pyrogenicity BRD: Section 1 2008. Disponível em: https://ntp.niehs.nih.gov/iccvam/docs/pyrogen/brd/1intro.pdf. Acesso: 28/05/2015.

PARDO-RUIZ, Z; MENÉNDEZ-SARDIÑAS DE; PACIOS-MICHELENA, A., et al. Soluble $\beta-(1,3)$ glucans enhance LPS-induced response in the monocyte activation test, but inhibit LPS-mediated febrile response in rabbits: Implications for pyrogenicity tests. European Journal Pharmaceutical Science, v. 30, n. 81, p. 16-28, 2015.

COOPER, J.F., WEARY, M.E., JORDAN, F.T. The impact of non-endotoxin LAL-reactive materials on Limulus amebocyte lysate analyses. PDA Journal Pharmaceutical Science Technology, v. 51, n. 1, p. 2-6, 1997.

MONTAG, T., SPREITZER, I., LOSCHNER, B., ET $A L$. Safety testing of cell-based medicinal products: opportunities for the monocyte activation test for pyrogens. ALTEX, v. 24, p. 81-89, 2007.

SPREITZER, I.; LÖSCHNER, B.; SCHNEIDER, C.K.; $E T A L .10$ years of experience with alternative pyrogen tests (monocyte activation tests). AATEX, 14, Special Issue, p. 587-589, 2007.

Rodapé:

${ }^{1}$ http://iccvam.niehs.nih.gov/methods/pyrogen/pyr_tmer.htm

${ }^{2} \mathrm{http}: / /$ www.marketssandmarkets.com

${ }^{3} \mathrm{http}: / / \mathrm{ww} w 2$. deloitte.com/content/dam/Deloitte/global/Document s/Life-Sciences-Health-Care/gx-Ishc-2015-life-sciences-report.pdf 